\title{
Efficacy of lamivudine in decompensated cirrhosis secondary to hepatitis B: Cautious optimism in the war not yet won
}

Eric M Yoshida MD MHSc FRCPC

\begin{abstract}
ARTICLE
Villeneuve JP, Condreay LD, Willems B, et al. Lamivudine treatment for decompensated cirrhosis resulting from chronic hepatitis B. Hepatology 2000;31:207-10.
\end{abstract}

\begin{abstract}
ARTICLE SUMMARY
A prospective single arm study was undertaken to determine whether lamivudine $(100 \mathrm{mg} / 150 \mathrm{mg}$ daily $)$ would result in improvement biochemically (serum aspartate aminotransferase, alanine aminotransferase, albumin, total bilirubin, prothrombin time) and clinically (change in Child-Pugh score) in 35 patients with chronic hepatitis B virus (HBV) infection (serum HBV-DNA positivity) and decompensated cirrhosis (Child-Pugh score 8 or higher; 10 Child class B, 25 Child class C). Five patients died of liver disease (baseline Child-Pugh score 12 to 13), seven underwent transplantation within six months. Of the remaining 23 patients, after six months, one underwent transplantation, two died (spontaneous bacterial peritonitis and hepatocellular carcinoma). After a mean follow-up of 19 months, there was improvement in bilirubin $(67 \pm 13$ to $30 \pm 4 \mathrm{mmol} / \mathrm{L}, \mathrm{P}<0.05)$, albumin $(27 \pm 1$ to $34 \pm 1 \mathrm{~g} / \mathrm{L}$, $\mathrm{P}<0.05)$ and Child-Pugh score $(10.3 \pm 0.4$ to $7.5 \pm 0.5, \mathrm{P}<0.05)$.
\end{abstract}

\section{COMMENTARY}

The long term prognosis for patients with decompensated cirrhosis is poor. For patients with chronic HBV, the therapeutic options include liver transplantation, which is limited by the current paucity of organs; low dose interferon, which is not very effective for Child's class B/C disease (1) and may cause further deterioration (2); or antiviral agents. Lamivudine is a well tolerated antiviral agent with efficacy in suppressing HBV replication (3). In the present study, lamivudine demonstrated efficacy in improving the clinical situation of patients with decompensated cirrhosis. These encouraging findings are tempered by the fact that $34 \%$ either died of liver disease or underwent transplantation within the first six months of the study. Furthermore, another three patients died of liver disease or required transplantation after six months. Clearly lamivudine can help some patients but does not replace timely referral for transplantation.

Another concern with the long term use of lamivudine is the development of YMDD motif lamivudine-resistant HBV strains. The Asian study group has reported the emergence of these mutants in approximately $40 \%$ after two years of lamivudine use (3). Although the YMDD mutant is considered less virulent than the wild-type strain (4), progressive liver disease can still occur (5), and active viremia with HBV remains a contraindication for transplantation in 
Canada. Fortunately, there is optimism for the future with the development of additional antiviral agents such as adefovir dipivoxil (6), which has demonstrated efficacy against wild-type and YMDD mutant HBV. Combination therapy, therefore, will be the future standard as hepatologists develop their own 'highly active antiretroviral therapies' for HBV.

\section{REFERENCES}

1. Perrillo R, Tamburro C, Regenstein F, et al. Low-dose, titratable interferon alfa in decompensated liver disease caused by chronic infection with hepatitis B. Gastroenterology 1995;109:908-16.

2. Nevens F, Goubau R, Van Eyken P, Desmyter J, Desmet V, Fevery J. Treatment of decompensated viral hepatitis B-induced cirrhosis with low doses of interferon alpha. Liver 1993;13:15-9.

3. Liaw YF, Leung NW, Chang TT, et al. Effects of extended lamivudine therapy in Asian patients with chronic hepatitis B. Asia Hepatitis Lamivudine Study Group. Gastroenterology 2000;119:263-6.

4. Melagari M, Scaglioni PP, Wands JR. Hepatitis B virus mutants associated with $3 \mathrm{TC}$ and famciclovir administration are replication defective. Hepatology 1998;27:628-33.

5. Yoshida EM, Ma MM, Davis JE, et al. Postliver transplant allograft reinfection with a lamivudine-resistant strain of hepatitis $B$ virus: long-term follow-up. Can J Gastroenterol 1998;12:125-9.

6. Perrillo R, Schiff E, Yoshida E, et al. Adefovir dipivoxil for the treatment of lamivudine-resistant hepatitis B mutants. Hepatology 2000;32:129-34.

\section{ADVERTISERS' INDEX}

The Canadian Journal of Gastroenterology is a peer review journal, financed almost entirely through advertising.

The companies advertising in this journal have recognized the need to support high quality, Canadian, ethical journals, and to promote publishing of Canadian medical research.

Pulsus Group Inc has established a number of ethical, peer review journals that provide a forum for the dissemination and discussion of vital medical research. The companies that support these journals through advertising are an integral part of furthering medical research and, therefore, improving health care for Canadians and others.

Pulsus Group and the readers of The Canadian Journal of Gastroenterology appreciate the support of the following companies for making this issue possible:

Axcan Pharma Inc

Salofalk

$\mathrm{OBC}$

Prescribing information $\quad 467$

Ferring Pharmaceuticals

Pentasa

Prescribing information

Schering

Hepatitis Update 424A

Solvay Pharma

Pantoloc

Prescribing information

IFC

468 


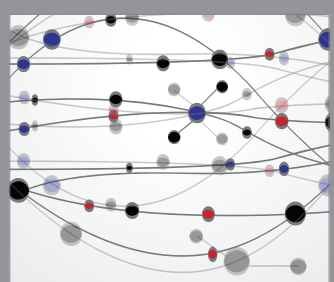

The Scientific World Journal
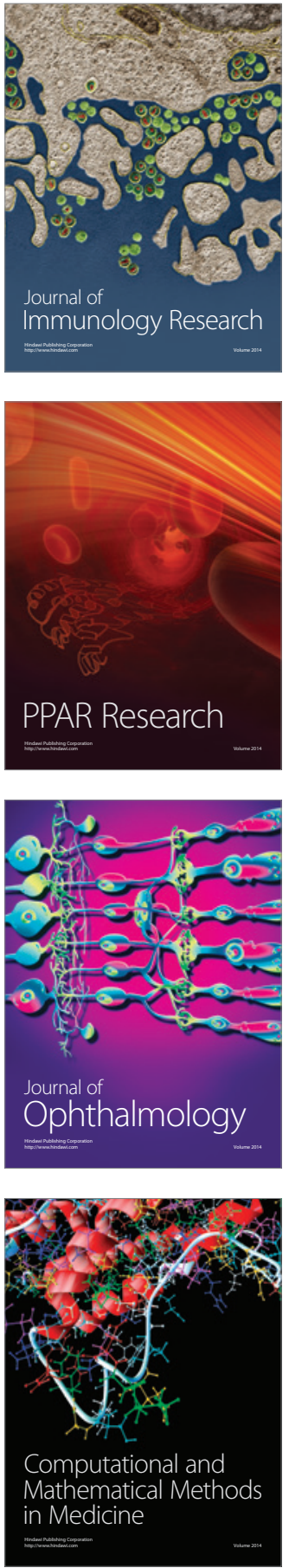

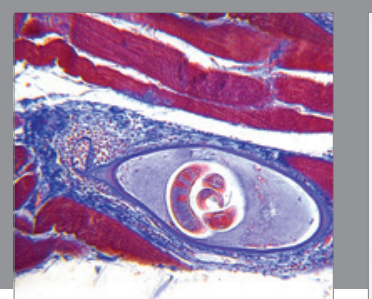

Gastroenterology Research and Practice

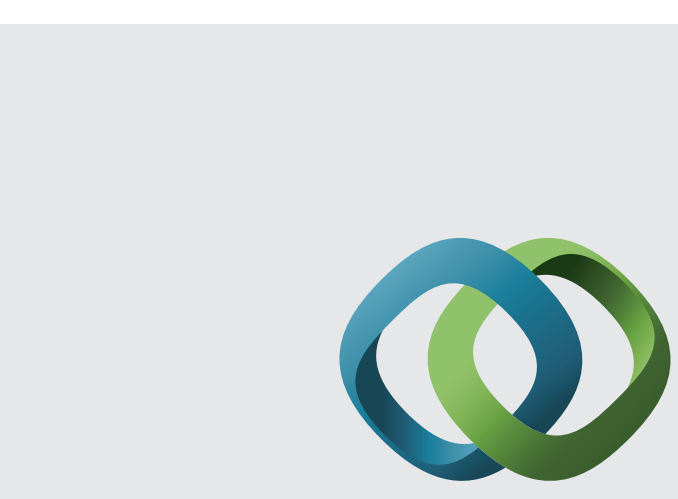

\section{Hindawi}

Submit your manuscripts at

http://www.hindawi.com
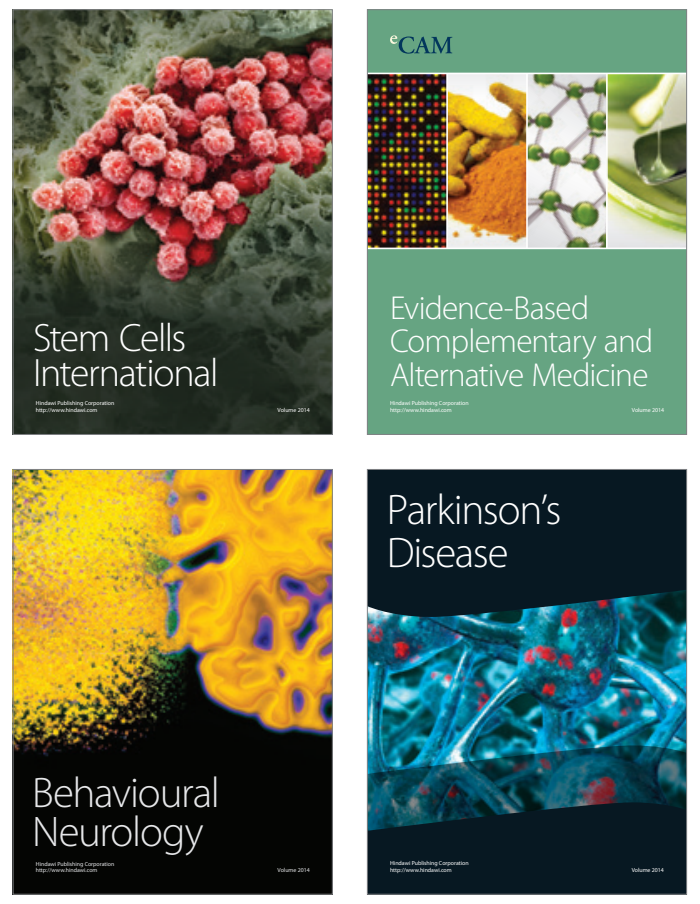
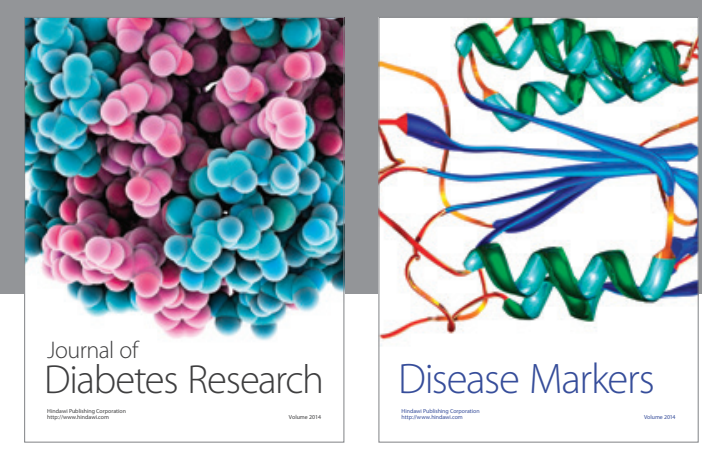

Disease Markers
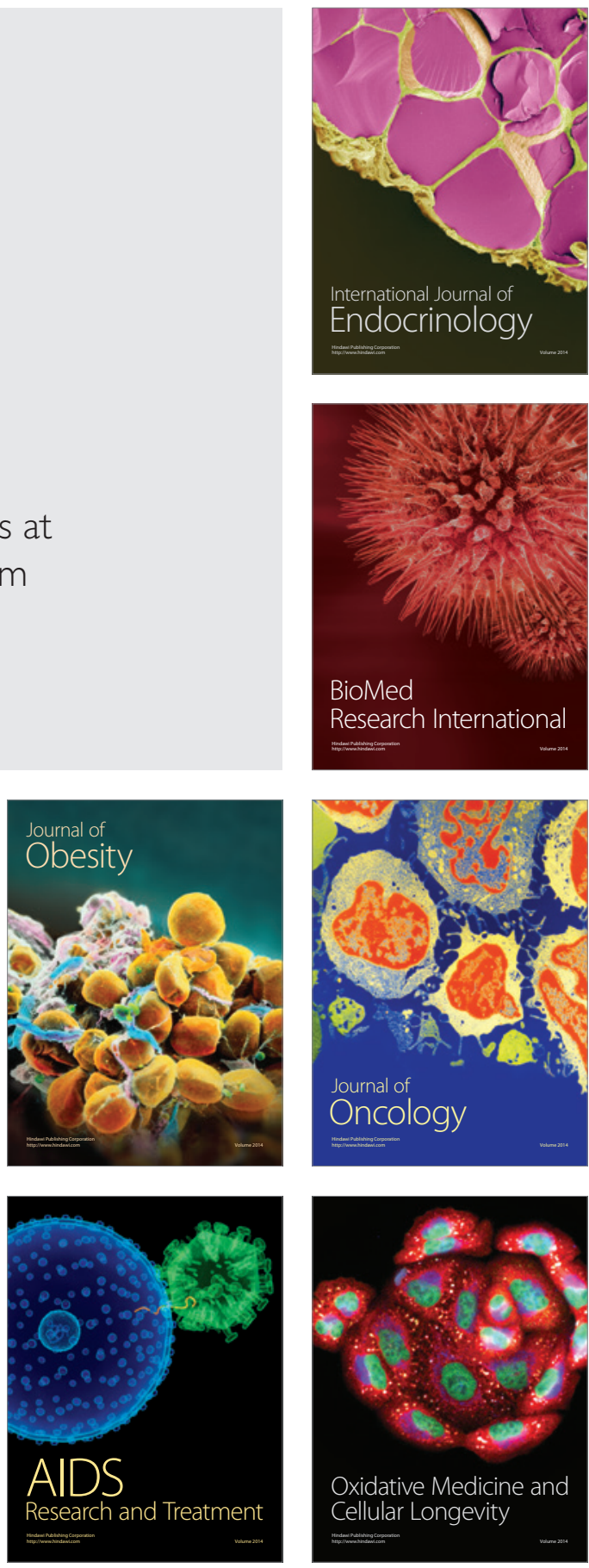